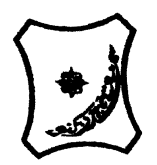

Bayero Journal of Pure and Applied Sciences, 12(2); 182 - 190

Received: June, 2019

Accepted: December, 2019

ISSN $2006-6996$

\title{
RELATIONSHIP BETWEEN FINGER PRINT PATTERNS WITH BLOOD GROUP AND GENOTYPE AMONG BASIC MEDICAL SCIENCE, STUDENTS OF BAYERO UNIVERSITY, KANO
}

\author{
Magaji H.S, Musa M.M Badamasi I.M* \\ Department of Anatomy, Faculty of Basic Medical Sciences, College of Medicine and Health and \\ Sciences, Bayero University Kano \\ *Corresponding author: badamasiibrahimmohammed@gmail.com
}

\begin{abstract}
Fingerprint patterns and the blood genotypes of individuals are chiefly determined by genetic factors during in-utero development. Evaluating genotypes requires expertise and facilities which could relatively be difficult to obtain and operate in some setting. The aim of the current study was to determine the correlation between hand finger print patterns and the common blood typing phenotype (genotype and blood group) among a group of consenting adult population in Nigeria. Four hundred students (217 males and 183 females) of the Faculty of Basic Medical Sciences in Bayero University Kano had their total hand fingerprints captured using a scanner / computer set up. Data regarding common blood phenotypes was also determined for all participants from the blood phenotype information on their University identification cards. The mean age of the participants was $21.86 \pm 3.37$ years. Loop finger prints patternwas the most common identified in the participants (58.4\%), followed by whorls (27.9\%), and then the least was arches $(13.7 \%)$. There was a significant association between the finger print pattern on the left thumb $(p=0.012)$ as well as right thumb $(p=0.013)$ withblood groups, while the print in the right index $(p=0.042)$ and left little finger $(p=0.024)$ were associated with genotypes in the participants respectively. There was a relationship between the finger prints patterns of the thumb, index finger and little finger with the common blood typing phenotypes. Thus, finger print patterns on the right index and left little finger correlates with blood genotypes.
\end{abstract}

Key words: Finger print, Genotype, Blood group, Correlation, Anthropometry

\section{INTRODUCTION}

Fingerprints are the impressions formed by the friction ridge of the human finger and they develop during the 12 th to $16^{\text {th }}$ weeks of embryonic development (Han et al, 2004; Reka, 2012). The final patterns of finger print are attained by the age 14 years or older and no two fingers have the same identical print (even identical twins with their similar DNA profile)(Hsieh et al., 2005; Nithin et al., 2009). Thus, fingerprint pattens are a very specific phenotypic manifestation of an underlying interplay of a population of genetic determinants and could thus be considered a sacrosanct for identification. There are 3 categories of fingerprint patterns that have been identified and they are; whorls, loops and arches (Galton, 1892).

A number of blood groups have been identified which vary in their distribution amongst various races of mankind (Mawuagi, 1999). In the clinical settings, only 'ABO' as well as 'Rhesus' groups are of major importance and the 'ABO' system is specifically comprised of the $A, B, A B$ and $\mathrm{O}$ blood group types based on the presence of a corresponding antigen in plasma (Pramanik and Pramanik,2000). The 'Rhesus' system is classified into 'Rh + ve' and 'Rh - ve' according to the presence or absence of ' $D$ ' antigen (Rastogi and Pillai, 2010). Another common phenotypic feature of blood type is called the genotype and it is a manifestation of the genetic makeup of an individual that involves a combination of alleles situated on corresponding chromosomes(Kinney 1991). Human blood genotypes were classified into;AA which is homozygous wild type (normal), AS which is heterozygous (carrier) type and SS is the homozygous mutant genotype that is pathognomonic of sickle cell disease (SCD) (Decie et al., 2006).

The relationship between blood group type and finger print patterns was also correlated (Sajad et al., 2016). Loops were highest in persons with blood group $A B$ at $61.76 \%$ and lowest in persons with blood group $\mathrm{O}$ at $48.08 \%$. And this was contrary to the findings in other studies (Bakare et al, 2006). In other studies, it was reported that the percentage of whorls, was 
BAJOPAS Volume 12 Number 2, December, 2019

high in persons with blood group $A$ at $45-39 \%$ and lowest in persons with blood group $O$ at 41.14\% (Shashikala and Ashwini, 2011). A study on the association between finger print pattern and genotype among Nigerians reported that radial and ulna loop pattern of finger print had the highest frequency among persons with $A A$ genotype while the frequency of loop finger print pattern was lowest in persons with SS genotype and it is moderate among persons with AS genotype (Ujaddughe et al,2016).

There is a dearth of data regarding the study subject among participants from Nigeria. The aim of the current study was to determine the relationship between finger print patterns with blood group and genotype among Basic medical science student of Bayero University kano, Nigerian.

\section{MATERIALS}

Computer(Laptop, Toshiba, China), Finger print scanner Device (Digital parsona, China), Proforma, USB(Toshiba, China)

\section{Study Protocol}

\section{Study Location and Participants}

The research was conducted in the Faculty of Basic Medical Sciences, Bayero University Kano. The recruitment of study participants was carried out within four weeks (one month).

\section{Inclusion Criteria}

Participants from faculty of Basic Medical Sciences whomust be aware of their blood group and genotype status, and they must be free from any deformity or pathology that affects the fingers.

\section{Exclusion Criteria}

Participants that are unaware of their blood group or Genotype and those with any deformity or pathology that affects the fingers prints

\section{Study Design/Sampling Method}

Cross sectional study with consecutive simple random sampling of participants

\section{Sample Size Determination}

The sample size was determined using a standard formula

(Lwanga and Lemeshow, 1991):

Where;

$n=\frac{z^{2} p q}{d^{2}} \quad n=\frac{( \pm 1.96)^{2} \times 0.5 \times 0.5}{(0.05)^{2}}=38$

Therefore, the minimum number of subjects needed for this study was 384 .

\section{Study Approval and Informed Consent}

Before commencement of the research, a study approval was obtained from the Department of Anatomy, Faculty of Basic Medical Sciences, College of Medicine and Health sciences, Bayero
University Kano. Verbal informed consent of the entire participant was obtained before they were recruited into the study.

\section{MATERIALS AND METHODS}

Paper towel cleaning of fingers was sufficient for removing dirt and grease that may interfare withclear and proper identification of finger print images. Imaging of the entire finger prints pattern was done for both hands by firmly applying a finger on the scanner one at a time to allow the individual images to be properly labelled and saved. An application system designed by ZKTeco Inc. China was modified by a software programmer using Microsoft Visual Basic 6.0 integrated development enrollment (IDE) was used to capture the fingerprints using the scanner device when connected to the computer system via Universal Serial Bus (USB). Details regarding the type of blood group as well as the type of genotype a study participant have were obtained from the university allocated identification card (ID) as well as their blood group and genotype self-report as declared in a proforma. The blood group and / or genotype records on the university allocated identification card (ID) were obtained from the mandatory laboratory and/ormedical screening exercise done for all undergraduate students at the point of first registration.

\section{Statistical Analyses}

The data obtained were presented as proportion/frequency. Chi-square test was used to test for the association between finger print patterns with blood group and genotype. The evaluation of the prediction of blood grouping and/or genotype using categorical data of the independent anthropometric variables was done using logistic regression. A statistical significance was considered when a $p$ - value was less than or equal to 0.05 . Statistical software for social sciences version 20.0 was used for statistical analysis.

\section{RESULTS}

The mean age of the study participants was $21.86 \pm 3.37$ years. Averagely, the most frequent fingerprints patterns in the entire 10 hand digits were loops $(58.4 \%$, range $=45-75 \%)$ ), followed by whorls $(27.9 \%$, range $=16.5-37.8 \%$ ) and arches $(13.7 \%$, range $=7.8-21.8 \%$ ) (Table 1).A similar distribution of print patterns was also observed when data was categorized based on gender (Table 1). 
BAJOPAS Volume 12 Number 2, December, 2019

Table 1: Distribution of finger print patterns of all the $\mathbf{1 0}$ digits among students of Faculty of Basic Medical Sciences, Bayero University, Kano.

\begin{tabular}{llllll}
\hline Finger pattern & Loop(L) (\%) & $\begin{array}{l}\text { Whorl(W) } \\
(\%)\end{array}$ & $\begin{array}{l}\text { Arch(A) } \\
(\%)\end{array}$ & $\begin{array}{l}\text { Males } \\
\text { L/W/A }\end{array}$ & $\begin{array}{l}\text { Females } \\
\text { L/W/A }\end{array}$ \\
\hline Right Thumb & $197(49.3)$ & $123(30.8)$ & $80(20)$ & $114 / 67 / 36$ & $83 / 56 / 44$ \\
Left Thumb & $180(45.0)$ & $133(33.3)$ & $87(21.8)$ & $99 / 70 / 48$ & $81 / 63 / 39$ \\
Right Index & $207(51.8)$ & $126(31.5)$ & $67(16.8)$ & $116 / 73 / 28$ & $81 / 54 / 48$ \\
Left Index & $204(51.0)$ & $116(29.0)$ & $80(20.0)$ & $123 / 62 / 32$ & $91 / 53 / 39$ \\
Right Middle & $255(63.8)$ & $101(25.3)$ & $44(11)$ & $142 / 57 / 18$ & $113 / 44 / 26$ \\
Left Middle & $260(65)$ & $90(22.5)$ & $50(12.5)$ & $152 / 48 / 17$ & $108 / 42 / 33$ \\
Right Ring & $213(53.3)$ & $151(37.8)$ & $36(9)$ & $120 / 82 / 15$ & $93 / 69 / 21$ \\
Left Ring & $222(55.5)$ & $147(36.7)$ & $31(7.8)$ & $124 / 83 / 10$ & $98 / 64 / 21$ \\
Right Little & $300(75)$ & $66(16.5)$ & $34(8.5)$ & $169 / 35 / 13$ & $131 / 31 / 21$ \\
Left Little & $297(74.3)$ & $66(16.5)$ & $37(9.3)$ & $164 / 36 / 17$ & $133 / 30 / 20$ \\
Overall total & $2335(58.4)$ & $1119(27.9)$ & $546(13.7)$ & & \\
\hline
\end{tabular}

The most frequent blood group among the male and female participants was blood group 0 (23.8 $28.3 \%)$, followed by blood group $A B(9-9.5 \%)$ and blood group $A(8-9 \%)$ while the least was group AB (5 - 7.5\%)(Table.2).

Table 2: Distributions of blood group and genotypes among students of Faculty of Basic Medical Sciences, Bayero University, Kano.

\begin{tabular}{lllllll}
\hline \multicolumn{3}{c}{ Blood groups } & \multicolumn{2}{c}{ Genotypes } \\
\hline Participants & O (\%) & AB (\%) & A (\%) & B (\%) & $\begin{array}{l}\text { AA (\%) } \\
\text { Normal }\end{array}$ & $\begin{array}{l}\text { AS + SS (\%) } \\
\text { Abnormal }\end{array}$ \\
\hline All & $208(52)$ & $50(12.5)$ & $72(18)$ & $70(17.5)$ & $288(72)$ & $112(28)$ \\
Males & $113(28.3)$ & $30(7.5)$ & $36(9)$ & $38(9.5)$ & $138(37.5)$ & $150(16.8)$ \\
Females & $95(23.8)$ & $20(5)$ & $36(9)$ & $32(8)$ & $45(34.5)$ & $67(11.3)$ \\
\hline
\end{tabular}

The most frequent genotype among male subject was the AA genotype, which made up to $37.5 \%$ of the entire study population and was categorized as normal genotype in the current study. Male participant having the AS and/or SS genotypes made up $16.8 \%$ of the entire study participants and this genotype was categorized as an abnormal genotype in the current study. In the entire study participants, $34.5 \%$ were females with the AA genotype, while $11.3 \%$ of them were females that have at least one Salleles in their genotype (Table 2).
In the evaluation of the distribution of blood group types based on the finger print patterns, the most frequent finger print pattern in all the fingers of left hand were loops (50\%-75\%), followed by whorls (20\%-35\%) and then the arches $(6 \%-18 \%)$ in all the participants. The finger print pattern on the left thumb was significantly $(p=0.012)$ associated with blood group types in the current study (Table 3 ). Specifically, the representation of the loop finger print patterns was significantly more than all the other patterns on the left thumb in patient with blood group $\mathrm{O}$ (Table 3 ). 
BAJOPAS Volume 12 Number 2, December, 2019

Table.3: Association of blood group and fingerprint patterns on the Left hand of students of Faculty of Basic Medical Sciences, Bayero University, Kano.

\begin{tabular}{lllllll}
\hline Finger & $\begin{array}{l}\text { Print } \\
\text { Patterns }\end{array}$ & $\mathbf{O}(\%)$ & AB (\%) & A (\%) & B (\%) & P-value \\
\hline Thumb & Loop & $111(27.8)$ & $20(5)$ & $25(6.3)$ & $24(6)$ & \\
& & & & & \\
& Whorl & $63(15.8)$ & $20(5)$ & $24(6)$ & $26(6.5)$ & \\
& Arch & $34(8.5)$ & $10(2.5)$ & $23(5.8)$ & $20(5)$ & \\
Index & Loop & $109(27.3)$ & $24(6)$ & $44(11)$ & $27(6.8)$ & \\
& Whorl & $64(16)$ & $14(3.5)$ & $16(4)$ & $22(5.5)$ & 0.101 \\
& Arch & $35(8.8)$ & $12(3)$ & $12(3)$ & $21(5.3)$ & \\
Middle & Loop & $134(33.5)$ & $34(8.5)$ & $46(11.5)$ & $46(11.5)$ & \\
& Whorl & $50(12.5)$ & $11(2.8)$ & $17(4.3)$ & $12(3)$ & 0.825 \\
\multirow{4}{*}{ Ring } & Arch & $24(6)$ & $5(1.3)$ & $9(2.5)$ & $12(3)$ & \\
& Loop & $113(28.2)$ & $28(7)$ & $48(12)$ & $33(8.2)$ & \\
& Whorl & $80(20)$ & $19(4.8)$ & $19(4.8)$ & $29(7.3)$ & 0.338 \\
& Arch & $15(3.8)$ & $3(0.8)$ & $5(1.2)$ & $8(2)$ & \\
& Loop & $157(39.2)$ & $34(8.5)$ & $53(13.3)$ & $53(13.3)$ & \\
& Whorl & $36(9)$ & $11(2.8)$ & $13(3.3)$ & $6(1.5)$ & 0.217 \\
& Arch & $15(3.8)$ & $5(1.3)$ & $6(1.5)$ & $11(2.8)$ & \\
\hline
\end{tabular}

The most frequent finger print pattern in all the fingers of right hand were loops (50\%-75\%), followed by whorls (20\%-35\%) and the least was arches (6\%-18\%) in all the participants irrespective of their blood group. The finger print pattern on the right thumb was significantly $(p=0.013)$ associated with the blood groups in the current study (Table 4). Specifically, the representation of the loopfinger print patterns was significantly more than all the other patterns on the right thumb in patient with blood group $\mathrm{O}$ (Table 4).

Table 4: Association of blood group and finger print patterns on the Right hand of students of Faculty of Basic Medical Sciences, Bayero University, Kano

\begin{tabular}{lllllll}
\hline Finger & $\begin{array}{l}\text { Print } \\
\text { patterns }\end{array}$ & $\mathbf{O}(\%)$ & AB (\%) & A (\%) & B (\%) & P-value \\
& & & & & \\
\hline Thumb & Loop & $127(29.3)$ & $22(5.5)$ & $34(8.5)$ & $24(6)$ & \\
& & & & & & 0.013 \\
& Whorl & $52(13)$ & $22(5.5)$ & $21(5.3 \%)$ & $28(7)$ & \\
& Arch & $39(9.8)$ & $6(1.5)$ & $17(4.3 \%)$ & $18(4.5)$ & \\
Index & Loop & $108(27)$ & $27(6.8)$ & $41(10.3)$ & $31(7.8)$ & 0.549 \\
& & & & & & \\
& Whorl & $70(17.5)$ & $13(3.3)$ & $20(5)$ & $23(5.8)$ & \\
Middle & Arch & $30(7.5)$ & $20(2.5)$ & $11(2.8)$ & $16(4)$ & \\
& Loop & $133(33.3)$ & $32(8)$ & $53(13.2)$ & $37(9.2)$ & 0.054 \\
& & & & & & \\
& Whorl & $55(13.8)$ & $14(3.5)$ & $14(3.5)$ & $18(4.5)$ & \\
& Arch & $20(5)$ & $4(1)$ & $5(1.3)$ & $15(3.8)$ & \\
& Loop & $113(28.2)$ & $24(6)$ & $45(11.3)$ & $32(7.8)$ & 0.071 \\
& & & & & & \\
& Whorl & $83(20.8)$ & $29(4.8)$ & $22(5.3)$ & $28(7)$ & \\
& Arch & $12(3)$ & $7(1.8)$ & $6(1.5)$ & $2.8(2.8)$ & \\
& Loop & $157(39.2)$ & $37(9.3)$ & $54(13.5)$ & $52(13)$ & 0.758 \\
& & & & & \\
& Whorl & $37(9.3)$ & $9(2.3)$ & $11(2.8)$ & $9(2.3)$ & \\
& Arch & $14(3.5)$ & $4(1)$ & $7(1.8)$ & $9(2.3)$ &
\end{tabular}


BAJOPAS Volume 12 Number 2, December, 2019

The most frequent finger print pattern in all fingers of right hand were loops (50\%-75\%), followed by whorls (20\%-45\%) and arches (7\%$30 \%$ ) was the least pattern in all participants irrespective of their genotype. The finger print pattern on the right index $(p=0.042)$ was significantly associated with genotypes in the current study (Table.5)

Table 5: Association of genotype and finger print pattern on the Right hand of students of Faculty of Basic Medical Sciences, Bayero University, Kano.

\begin{tabular}{lllll}
\hline Finger side & $\begin{array}{l}\text { Print } \\
\text { Patterns }\end{array}$ & $\begin{array}{l}\text { Normal Genotype } \\
\text { AA (\%) }\end{array}$ & $\begin{array}{l}\text { Abnormal Genotype } \\
\text { (SS and SS)\% }\end{array}$ & P-value \\
\hline Thumb & Loop & $142(35.5)$ & $44(13.8)$ & \\
Right & Whorl & $88(22)$ & $35(8.7)$ & \\
& Arch & $58(14.5)$ & $22(5.5)$ & 0.988 \\
Index & Loop & $152(38)$ & $55(13.8)$ & \\
& Whorl & $96(24)$ & $30(7.5)$ & \\
& Arch & $40(10)$ & $27(6.7)$ & \\
Middle & Loop & $188(47)$ & $67(16.8)$ & \\
& Whorl & $71(17.8)$ & $30(7.5)$ & \\
& Arch & $29(7.2)$ & $15(3.7)$ & 0.042 \\
Ring & Loop & $161(40.3)$ & $52(13)$ & \\
& Whorl & $106(26.5)$ & $45(11.3)$ & \\
& Arch & $21(5.2)$ & $15(3.8)$ & \\
Little & Loop & $212(53)$ & $88(22)$ & \\
& Whorl & $54(13.5)$ & $12(3)$ & \\
& Arch & $22(5.2)$ & $13(3)$ & \\
& & &
\end{tabular}

The most frequent finger print pattern in all the fingers of left hand were loops (50\%-75\%), followed by whorls (20\%-45\%) and arches (7\%$30 \%$ ) was the least in all the participants irrespective of their genotype. The finger print pattern on the left little finger $(p=0.024)$ was significantly associated with genotypes in the current study (Table.6).

Table 6: Association of genotype and fingerprint pattern on the Left hand of Students of Faculty of Basic Medical Sciences, Bayero University, Kano.

\begin{tabular}{lllll}
\hline Finger & $\begin{array}{l}\text { Print } \\
\text { patterns }\end{array}$ & $\begin{array}{l}\text { Normal Genotype } \\
\text { AA (\%) }\end{array}$ & $\begin{array}{l}\text { Abnormal Genotype } \\
\text { (AS and SS) \% }\end{array}$ & P-value \\
\hline Thumb & Loop & $136(34)$ & $44(11)$ & \\
& Whorl & $94(23.5)$ & $39(9.8)$ & 0.291 \\
& Arch & $58(14.5)$ & $29(7.2)$ & \\
Index & Loop & $154(41)$ & $50(12.5)$ & 0.09 \\
& Whorl & $84(21)$ & $32(8)$ & \\
& Arch & $50(12.5)$ & $30(7.5)$ & 0.755 \\
Middle & Loop & $184(46)$ & $76(19)$ & \\
& Whorl & $67(16.8)$ & $23(5.8)$ & 0.307 \\
& Arch & $37(9.2)$ & $23(3.2)$ & $<0.024$ \\
& Loop & $159(39.8)$ & $63(15.8)$ & \\
& Whorl & $110(27.5)$ & $37(9.2)$ & \\
& Arch & $19(4.7)$ & $12(3)$ & \\
& Little & $213(53.5)$ & $84(21)$ & \\
& Whorl & $54(13.5)$ & $12(3)$ & \\
& Arch & $21(5.2)$ & $16(4)$ & \\
\hline
\end{tabular}

The evaluation of the association between the independent variables (finger print patterns in the entire 10 digits of the hand) with the genotype of study participants was presented in Table 7. 


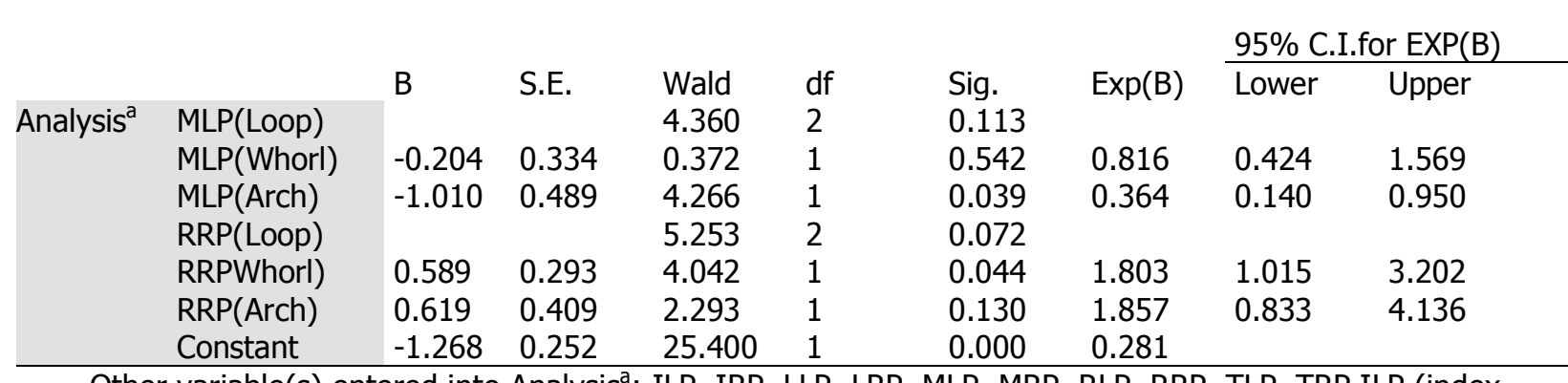

Other variable(s) entered into Analysis ${ }^{\mathrm{a}}$ : ILP, IRP, LLP, LRP, MLP, MRP, RLP, RRP, TLP, TRP.ILP (index left print), IRP (index right print), LLP (Little left print), LRP (Little right print), MLP (Middle left print), MRP (Middle right print), RLP (ring left print), RRP (Ring ring print), TLP (Thumb left print), TRP (Thumb right print).

The evaluation for the association between the finger print patterns in the entire 10 digits of the hand with the blood group types was carried out in this study and presented in Table 8.

Table 8: The logistic regression evaluation of the association between finger print pattern in the entire 10 fingers and blood group type of study participants.

\begin{tabular}{|c|c|c|c|c|c|c|c|c|c|}
\hline \multirow{2}{*}{\multicolumn{2}{|c|}{ Blood group type }} & \multirow{3}{*}{$\frac{B}{-1.013}$} & \multirow{3}{*}{$\begin{array}{l}\text { Std. } \\
\text { Error } \\
0.959\end{array}$} & \multirow{3}{*}{$\begin{array}{l}\text { Wald } \\
1.118\end{array}$} & \multirow[b]{2}{*}{$\mathrm{df}$} & \multirow{3}{*}{$\frac{\text { Sig. }}{0.290}$} & \multirow[b]{2}{*}{$\operatorname{Exp}(B)$} & \multicolumn{2}{|c|}{$95 \%$ CI for $\operatorname{Exp}(B)$} \\
\hline & & & & & & & & $\begin{array}{l}\text { Lower } \\
\text { Bound }\end{array}$ & $\begin{array}{l}\text { Upper } \\
\text { Bound }\end{array}$ \\
\hline AB blood & Intercept & & & & 1 & & & & \\
\hline \multirow[t]{3}{*}{ type } & [TRP=Loop] & 0.888 & 0.605 & 2.156 & 1 & 0.142 & 2.430 & 0.743 & 7.946 \\
\hline & {$[\mathrm{TRP}=$ Whorl $]$} & 1.812 & 0.644 & 7.913 & 1 & 0.005 & 6.120 & 1.732 & 21.623 \\
\hline & [TRP=Arch] & $0^{b}$ & & & 0 & & & & 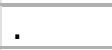 \\
\hline \multirow{4}{*}{$\begin{array}{l}\text { A blood } \\
\text { type }\end{array}$} & Intercept & -1.033 & 0.862 & 1.436 & 1 & 0.231 & & & \\
\hline & [TLP=Loop] & -1.394 & 00.462 & 9.116 & 1 & 0.003 & 0.248 & 0.100 & 0.613 \\
\hline & {$[\mathrm{TLP}=$ Whorl $]$} & -0.769 & .474 & 2.633 & 1 & 0.105 & 0.463 & 0.183 & 1.173 \\
\hline & {$[\mathrm{TLP}=\mathrm{Arch}]$} & $0^{\mathrm{b}}$ & & & 0 & & & & \\
\hline \multirow{4}{*}{$\begin{array}{l}\text { B blood } \\
\text { type }\end{array}$} & Intercept & 1.057 & 0.686 & 2.372 & 1 & 0.124 & & & \\
\hline & [LLP=Loop $]$ & -0.710 & 0.515 & 1.903 & 1 & 0.168 & 0.491 & 0.179 & 1.349 \\
\hline & [LLP= Whorl $]$ & -1.548 & 0.691 & 5.014 & 1 & 0.025 & 0.213 & 0.055 & 0.824 \\
\hline & {$[\mathrm{LLP}=\mathrm{Arch}]$} & $0^{\mathrm{b}}$ & & & 0 & & & & \\
\hline
\end{tabular}

a. The reference category is Blood group type $O$. $b$. This parameter is set to zero because it is redundant. Other variable(s) entered into Analysis ${ }^{a}$ : ILP, IRP, LLP, LRP, MLP, MRP, RLP, RRP, TLP, TRP. ILP (index left print), IRP (index right print), LLP (Little left print), LRP (Little right print), MLP (Middle left print), MRP (Middle right print), RLP (ring left print), RRP (Ring ring print), TLP (Thumb left print), TRP (Thumb right print).

\section{DISCUSSION}

In the current study, the mean age of the study participants was $21.86 \pm 3.37$ years. The loop finger print patterns was the commonest (58.4\%), followed by whorls $(27.9 \%)$ and then arches $(13.7 \%)$. Blood group $O$ was very common among the females (23.8\%) as well as the males $(28.3 \%)$ when compared to the low (9\%)value of the entire study participants (females and males)with group A blood type. It was also higher than the $8-9.5 \%$ value of theparticipants (females and males) with group B blood type in the current study. Thus, the study participants blood type can be depicted as
$\mathrm{O}>\mathrm{A}>\mathrm{B}>\mathrm{AB}$. In the entire study participants, $34.5 \%$ were females with the normal genotype (AA) while $37.5 \%$ were males with similar genotype. The proportion of females with abnormal genotype (AS and SS) in the study population was $11.3 \%$ while the rest of the participants $(16.8 \%)$ were males with abnormal genotype. Among the entire study population, participants with blood group $\mathrm{O}$ and A commonly (55\%-75\%) had a loop finger print pattern. Participants with whorl finger print pattern that also express either blood group $\mathrm{O}$ or A made up $25 \%-35 \%$ of the entire study participants. 
BAJOPAS Volume 12 Number 2, December, 2019

The proportion of participants that have the arch finger print pattern as well as the group $\mathrm{O}$ or $\mathrm{A}$ blood type made up $6 \%-18 \%$ of the entire participants. The proportions of participants expressing the group $\mathrm{O}$ blood type as well as the loop finger print pattern is always higher than the proportions of participants expressing the group Ablood type along with the loop finger print pattern. A high frequency of loops finger print $(50 \%-75 \%)$, followed by whorls (20\%$45 \%$ ) and arches (7\%-30\%) was observed in participant with normal genotype (AA).

In an earlier study of the Okrika ethnics people, it was reported thatthe proportions of different finger print patterns were $46.42 \%$ loops, $37.77 \%$ whorls and $14.12 \%$ arches. Among the people of the Ikwere ethnic group, the proportions of different finger print patterns were $50.46 \%$ loops, $24.42 \%$ whorl and $15.89 \%$ arches (Osunwonke et al, 2008). These literature reports were similar to the results in current study and this is probably because both studies recruited Nigerians as participants.

The distribution of blood type was evaluated in the literatureand it suggested that the proportion of participants with blood group $\mathrm{O}$ (46 - 55.3\%),blood group A (25.3 - 27.0\%), blood group B $(7.0-16.7 \%)$ and blood group $A B(2-2.7 \%)$ were stable among Africans and people of African descent (Seeley et al,1998; Adebayo and Soboyejo 2006). In another study carried out among a large population of participants in Ogbomoso, Oyo State, Nigeria, half of the participants evaluated had blood group O blood type, $22.9 \%$ blood group A blood type; $21.3 \%$ blood group B blood type and $5.9 \%$ blood group AB blood type (Bakare et al., 2006). Some studies carried out among Indians revealed a similar result regarding the proportions of the blood group types in the study population (Thomas and Shenoy, 2013; Manikandan et al., 2019). There are studies among Indians that revealed a higher proportion of group $B$ blood type and not group $O$ (Pasha et al., 2009; Rizwan et al., 2017). A study had reported a higher frequency for blood group $A$ (46\%) as opposed to blood group O (32\%) (Shashikala and Ashwini, 2011). The identification of a similar distribution forblood group types in Indians like in Nigerians, as well as the identification of other different distributions patterns among Indians and the identification of an entirely different pattern among Turks, discredits the "African descent" explanation as a basis for the differences.

The similarity of the findings of the current study with those that revealed a higher proportion of participants with blood group Oas opposed to the studies that had more participants with blood group A may be entirely associated with the multifactorial and / or environmental factors. The proportion of participants in an earlier study that had the normal (AA) genotype was $70 \%$ while the remaining participants $(30 \%)$ had the AS and / or SS (Abnormal genotype) genotype and this is similar to the findings in the current study (Adeyemo and Sobeyejo, 2006; Egesie et al., 2008). The similarity may be because the participants are black Africans domiciled in malaria endemic region of the world.

The high proportion of loop finger print pattern as well as the very low proportion of the arch finger print pattern in the current study was similar to the distribution of finger print pattern reported in the literature (Bharadwaja et al, 2004; Patel and Bhoot, 2016; Narayana et al., 2016). The distribution of loop finger print pattern was generally higher in all the participants with the blood type $\mathrm{O}$ irrespective of the finger. The loop finger print pattern on the right thumb $(p=0.013)$ and left thumb $(p=0.012)$ were significantly associated with the blood group type(blood type O) among study participants. Earlier literature had reported that the left and right little finger have the highest proportions of loop pattern while the proportion of loop pattern from the right index finger was the least, and this finding was irrespective of the $A B O$ blood group types of the participants. The loop pattern in these fingers was higher than the highest proportions of whorl identified in the right ring finger or the highest proportion of arch identified in the left index finger (Thomas and Shenoy, 2013; Sahu et al., 2016). In another study, the occurrence of loop finger print pattern was highest in all the blood types of the study participants except the $\mathrm{O}^{-}$blood type which had more Whorls than loops finger print pattern (Rastogi and Pillai, 2012). Although these earlier studies failed to evaluate the level of statistical significance, nevertheless, the findings especially as it pertains to the $\mathrm{O}^{+}$blood group and its association with loop finger print pattern is maintained.

In the current study, the high proportion of the loop finger print pattern was maintained irrespective of the type of genotype (normal AA and abnormal (AS and/or SS) genotypes) the participant has and this finding was similar to that of an earlier study (Ujaddughe et al, 2016). Nevertheless, only the association between the finger print patterns for the right index finger $(p=0.042)$ and left little finger $(p=0.024)$ with genotypes was statistically significant $(P \leq 0.05)$. Thus, participants with the normal genotypes as well as loop finger print pattern were significantly more than the proportion of participants with the abnormal genotype as well 
BAJOPAS Volume 12 Number 2, December, 2019

as the loop finger print pattern. Participants with whorl in the right ring finger were at increased odd for having an abnormal genotype while those with arch on the middle left finger have increased odd for having normal genotype. The right thumb whorl print pattern was a good predictor for group $A B$ blood type rather than the group $O$ blood type when compared to the arch thumb finger print pattern and the association was statistically significant $(P=$ $0.005, \mathrm{OR}=6.12,(\mathrm{CI}=1.73-21.63)$. The blood type

is more likely to be $A$ rather than $O$ if the finger print pattern in the left thumb is arch and not loop and the evaluation was statistically significant $(P=0.03, O R=0.248, C I=0.100-$ $0.613)$. Similarly, the blood type is $B$ and not $O$ if the left little finger print pattern is arch and not the whorl and the assessment was statistically significant $(P=0.025, O R=0.213, C I=0.055-$ $0.824)$. Thus arch finger print pattern in the left little finger as well as the left thumb predicts the $B$ and $A$ blood types. Whorl on right thumb predicted blood type $A B$ while whorl finger print pattern in right ring finger predicted abnormal genotype. These are novel statistical findings that were extracted by applying the principles of logistic regression in the assessment. In earlier studies targeted at determining the association between dermatoglyphics pattern and SCD among Nigerians, more whorls were reported among male SCD patients (Oladipo et al., 2007; Ramesh et al., 2012). Total absence of radial loop among female participant with SCD as well as absence of significant difference in the

\section{REFERENCES}

Adeyeomo, O.A and Soboyejo, O.B. (2006). Frequency distribution of $\mathrm{ABO}, \mathrm{RH}$ blood groups and blood groups and blood Genotypes Among the cell Biology and Genetics. African Journal of Biote Chromology, 5(22). 2062.

Bakare,A.A., Azeez,M.A and Agbolade,J.O. (2006). Gene frequencies of $A B O$ frequencies of $A B O$ and rhesus blood groups and haemoglobin variants in Ogbomoso, south-west Nig. African Journal of Biotechnology ,5(3):224 -229

Bharadwaja, A., Saraswat, P.K., Agrawal,S.K., Banerji,P and Bharadwaj,S.(2004). Pattern of fingerprints in different $A B O$ blood groups. Journal for Forensic Medicine and Toxicology, 21(2):49e52

Lewis, S. M., Bain, B. J., Bates, I (editors). Dacie and Lewis practical haematology.In distribution of finger print patterns among the $\mathrm{SCD}$, sickle cell trait and normal participants were also reported in the literature (Ramesh et al., 2012). Although, there are differences in the scope of the current study as well as those of the earlier studies, the earlier study strengthens the current finding that suggests that whorl finger print pattern may predict for abnormal hemoglobin genotype. Even though statistical evaluation of the association of finger print pattern for each digit with individual blood type were not ascertained in the literature, a trend for such a correlation had been reported severally. The print pattern in the ring finger of participants with blood type $A, B, A B$ and $O$ was mainly whorl while as the loop pattern predominates the middle and little finger print patterns irrespective of the blood group type (Bharadwaja et al., 2004). Thus, further emphasizing the feasibility of findings of a role for finger print pattern in prediction of genotype and blood group as in this study.

\section{CONCLUSION}

Finger print patterns were determined; blood group and genotype among study participant were reported. The study also revealed an association between finger print pattern with blood group type as well as genotype of study participants. Arch finger print pattern in the left little finger as well as the left thumb predicts the $B$ and $A$ blood types. Whorl on right thumb predicted blood type $A B$ while whorl finger print pattern in right ring finger predicted abnormal genotype.

Chapter 19 - Blood cell antigens and antibodies: erythrocytes, platelets, and granulocytes. Churchill livingstone. 10 th edition: 481-522

Lwanga, S. K., Lemeshow, S., \& World Health Organization. (1991). Sample size determination in health studies: a practical manual. World Health Organization.

.Egesie U g., Egesie $\mathrm{O}$ J., Usar I., and Johnbull T O (2008). Distribution Of ABO, Rhesus Blood Groups and Haemoglobin Electrophoresis among the Undergraduate Students Of Niger Delta University Nigeria. Nigerian Journal of Physiological Sciences 23 (1-2):5 - 8 (C) Physiological Society of Nigeria, 2008. Available online/abstracted at http://www.bioline.org.br/np; ww.ajol.info/journals.nips; www.cas.org 
BAJOPAS Volume 12 Number 2, December, 2019

Galton, F. (1892). Finger Prints. London: Macmillan and Co.Chapter 5 page 78

Han, Y., Ryu, C., Moon, J., Kim, $\mathrm{H}$ and Choi, $\mathrm{H}$. (2004). A Study on Evaluating the Uniqueness of Fingerprints Using Statistical Analysis. InformationSecurity and Cryptology-ICISC, 467-477.

Hsieh, C.T. Shyu, S.R and Hue C.S. (2005).An Effective Method of Fingerprint Classification Combined with AFIS. In: Yang L.T., Amamiya M., Liu Z., Guo M., Rammig F.J. (eds) Embedded and Ubiquitous Computing - EUC 2005. EUC 2005. Lecture Notes in Computer Science, vol 3824. Springer, Berlin, Heidelberg

Kinney, T.R. (1991). Pain in sickle cell disease. Rates and risk factors. New England Journal of Medicine, 325:11-15.

Manikandan S, Devishamani L., Vijayakumar S., Palanisamy G S., Ponnusamy P., and Jayaka S L L (2019). Dermatoglyphics and Their Relationship with Blood Group: An Exploration. J Pharm Bioallied Sci. 11(Suppl 2): S285-S288.doi: 10.4103/JPBS.JPBS_13_19

Mawuagi, J. (1999). Blood group distribution in an urban population of patient targeted blood donors. East African Medicine Journal, 76(11):615 --618.

Narayana BL, Rangaiah YKC, and Khalid MA. Study of fingerprint patterns in relation to gender and blood group. J. Evolution Med. Dent. Sci. 2016;5(14):630-633, DOI: $10.14260 /$ jemds/2016/144.

Nithin,M.D., Balaraj., B.M. Manjunatha, B. and Mestri S.C.(2009). Study of Fingerprint Classification and their Gender Distribution among South Indian Population. Journal of Forensic and Legal Medicine, 16(8): 460463

Oladipo, G. S and Ogunnowo, M. B. (2004). Dermatoglyphic patterns in diabetes mellitus in south eastern Nigerian population. African Journal of Applied Zoology and Environmental Biology, 6:610

Osunwoke, E. A., Ordu, K. S., Hart, J., Esomonu, E and Tamunokuro, F. B. (2008). A study on the dermatoglyphic patterns of Okrika and Ikwerre ethnic groups of Nigeria. Scientia Africana. Vol. 7, Number 2. Pp. 143-147.

Pasha A K., Hashir M M., and Khawar S (2009). Frequency of $A B O$ blood groups among medical students at the department of physiology and medicine at Nishtar medical college (NMC) Multan. Journal of surgery Pakistan (international). 14(2)

Patel D J and Bhoot R R (2016). A Study of Different Finger Print Patterns in $A B O$
Blood Groups. Indian Journal of Forensic Medicine \& Toxicology. 10 (2). DOI Number: 9130.2016.00117.1

$10.5958 / 0973-$

Pramanik, T and Pramanik ,S. (2000). Distribution of $\mathrm{ABO}$ and $\mathrm{Rh}$ blood groups in Nepalese students: a report. Eastern Mediterranean Health Journal. 6(1):156 - 158.

Ramesh M., Kumari K G., Kalpana V L., and Sudhakar G (2012). Palmar And Digital Dermatoglyphic Patterns in Sickle Cell Anemia Patients of North Coastal Andhra Pradesh, South India. Antrocom Online Journal of Anthropology.8.(1):1973 - 2880

Rastogi $P$, and Pillai $K R$ (2012). A study of fingerprints in relation to gender and blood group. J Indian Acad Forensic Med, 32(1) ISSN 0971-0973 11

Reka, R. (2012). Automatic Overlapped Fingerprint Separation. International Journal of Computer Science and Information Technology \& Security (IJCSITS), 2(2): 285.

Rizwan A. Kamle, S.B. Bhoi, S.A. Waghmare, S.K. Meshram, K.B. Shirsat (2017). Correlation of finger prints with blood groups as an identity tool. Indian Journal of Forensic Medicine and Pathology. 10 2. DOI: http://dx.doi.org/10.21088/ijfmp.0974.338 3.10217.12

Sahu M., Tiwari A and Rao I A (2016). Distribution of Fingerprint Patterns in Different $A B O$ Blood Groups. International Journal for Research in Emerging Science and Technology. 3.

Sajad,H.R., Ashfaqul,H., Saba .Y and Mubeen ,R.(2016). Pattern of fingerprint in Different Blood Group among first year medical student. Scholars' Journal of Applied Medical Sciences, 4(7d):25752578.

Seeley,R.R.,Stephens,T.D and Tate,P. (1998). Anatomy and Physiology. 4th edition. The McGraw Hill Companies, Inc. USA p. 1098.

Shashikala,J.R.L and Ashwini S. J (2011). Digital dermatoglyphic and ABO blood groups," Indian Journal of Forensic Medicine and Pathology, vol. 4, no. 2, pp. 77-81.

Thomas R., and Shenoy S J. (2013). Dermatoglyphics and ABO Blood Groups, an Observational Study. Medico-Legal Update, 13(1) 106-110

Ujadaddughe M.O., Otamre, H.O., Olerenwaju, D.O., Anura. A, Oriakhi $\mathrm{O}$ and Nawaimo V.O(2016).Correlation between fingerprint ABO-Blood group and Haemoglobin Genotype of Voluntary Blood donors in ISTH,Irua Edo State,Nigeria.. JOURNAL OF ANATOMY: 236:351-352. 